\title{
The EdD and the Scholarly Practitioner The CPED Path
}

\author{
Maximilian T. Schuster \\ University of Pittsburgh \\ mts31@pitt.edu
}

Perry, J. A. (Ed.). (2016). The EdD and the scholarly practitioner: The CPED
path. Charlotte, NC: Information Age Publishing. 234 pp.
Paperback: $\$ 45.99$. ISBN: 978-168123-541-7.

This volume, edited by Jill Alexa Perry, delivers a framework for EdD restructuring from the Carnegie Project on the Education Doctorate (CPED), a collective of $100+$ colleges and universities in the United States, Canada, and New Zealand that is focused on preparing scholarly practitioners through a reimagined, yet flexible EdD framework. The framework presented is altogether utile, theoretical, and practical, and Perry's volume provides a cohesive path for transformative EdD reform. The text tackles tensions that have long existed between $\mathrm{PhD}$ and $\mathrm{EdD}$ education and outlines ways in which an EdD curriculum can be redesigned to prepare scholarly practitioners for transformational leadership roles within education. The volume's thoughtful consideration of the depth of issues that surround EdD reform allow the CPED framework to be transferable to multiple institutional contexts, which strengthens its utility for multiple audiences.

This volume contains 13 chapters with an introductory chapter by the volume editor that describes transformational leadership approaches in CPED-influenced EdD programs that develop scholarly practitioners. The first section, Tools for Considering EdD Program Redesign, makes manageable the process for reimagining an EdD program. Specifically, the section proposes reflexive questions for program faculty to consider, strategies for leveraging leadership to support programmatic changes, and curricular tools for program redesign. The second section, Highlights from CPEDInfluenced Programs, handily considers the successes of CPED institutions mostly related to their implementation of the reconsidered dissertation of practice. The final section, In Their Own WordsExperiences of Scholarly Practitioners, uniquely explores through CPED-influenced EdD graduates' voices the dissertation of practice's influence on graduates' development as scholarly practitioners. Throughout the volume are details and examples of signature pedagogical techniques unique to the CPED framework. These examples are supported by CPED data and rich qualitative examples that highlight instances where the CPED framework created effective laboratories of practice for EdD students. For example, Chapter 9, The Role of Research Courses, by Belzer, Axelrod, Benedict, Jakubik, Rosen and Olcay presents two sets of datasets from CPED institutions that demonstrate the utility of the realigned methodology courses.

Located within the first section, chapter 4, Building and Sustaining a Learning Cohort, by Browne-Ferrigno and Maughan is especially worth highlighting because it provides an essential and unique overview of the CPED-influenced learning cohort model that promotes peer collaboration and cooperative learning. This signature pedagogy maintains soundness and the chapter authors aptly outline generative strategies that produce successful outcomes as well as expected obstacles to cohort implementation. Chapter 5, Mentoring Students in CPED-Influenced Doctoral Programs, by Ewbank is, likewise, noteworthy because of its description of mediating faculty engagement through sustained and integrative mentoring relationships. For CPED-influenced programs, these effective relationships occur before, during, and beyond a student's enrollment in an EdD program. Combined with other key curricular designs detailed later in the text, such as offering practical research courses and producing a dissertation of practice, these chapters contribute to a unified framework that is neither static nor fixed. Instead, the framework's adhesion to core CPED principles allow its specific implementation to remain fluid and flexible in order to meet the demands of individual institutions contexts.

New articles in this journal are licensed under a Creative Commons Attribution 4.0 United States License.

This journal is published by the University Library System of the University of Pittsburgh as part of its D-Scribe Digital Publishing Program and is cosponsored by the University of Pittsburgh Press.

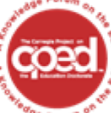

This journal is supported by the Carnegie Project on the Education Doctorate: A Knowledge Forum on the EdD (CPED) cpedinitiative.org
ISSN 2472-5889 (online) DOI 10.5195/ie.2017.34 
The second section of this volume provides examples of the CPED framework, focusing heavily on dissertations reimagined as actionable research to practice projects. These projects intend to prepare scholarly practitioners through the development of new knowledge, skills, and dispositions that are harnessed through creative curricular designs and meaningful final products. This section envisions EdD dissertations as the combination of rigorous research, timely problems of practice, and students' academic and professional interests. Chapter 11, The Single-District Dissertation, by Hochbein serves as a section exemplar by explaining how several EdD students at a CPEDinfluenced program utilized their dissertations to bridge research and practice. In particular, these students investigated increases in their school district's statewide math testing and concluded the mechanism that drove the growth of those results. Their projects illustrate how dissertations of practice can reduce the distance between theory and practice. These chapters highlight practices from successful CPED EdD programs, blending theoretical and practical aspects, to sketch a blueprint for a revitalized EdD dissertation process.

The volume concludes with several accounts of the experiences and perspectives of scholarly practitioners who completed a CPED-influenced EdD. These chapters not only provide a refreshing student perspective that connects to previous chapters, but they also detail the ways in which these students experienced the signature pedagogies of their programs. This section heavily focuses on students' dissertation experiences, underscoring how action research dissertations aid in preparing scholarly practitioners. This section's almost exclusive focus on students' dissertation experiences does, however, leave the reader yearning for more depth about students' other experiences with their cohorts, faculty mentoring relationships, and research methods courses.

Overall, this volume provides a veritable path for EdD reform and redesign at the institutional and programmatic levels. Presenting theoretical and practical evidence through rich qualitative data provides EdD program faculty and administrators with actionable steps aimed at transforming their programs to develop scholarly practitioners. Perhaps most helpful, this volume presents a framework for EdD reform; it is not a stringent manual. It considers and tackles contentious issues and tensions between the EdD and PhD, while describing core principles that found CPED-influenced doctoral programs. The principles, considered alongside these tensions, make the process of EdD curriculum reform more tangible. The framework's transferability and adaptability to different institutional contexts serves as its ultimate strength.

While this text engages in a timely and relevant discussion about the EdD, several critiques exist. At times, the qualitative data presented serves more descriptive rather than analytical purposes, relying on demonstrating examples instead of undertaking critical interrogation. At other times, implications derived from data are best suited for an institution already within CPED instead of an institution beginning reform efforts. Finally, the findings described in several chapters are not compared to non-CPED EdD programs, potentially dampening support for CPED-influenced EdDs. Despite these critiques, The EdD and the scholarly practitioner: The CPED path provides an instructive and practicable guide for institutions and EdD programs to begin this necessary journey in order to prepare scholarly practitioners for the transformational leadership that our education systems greatly deserve.

Impacting Education: Journal on Transforming Professional Practice 